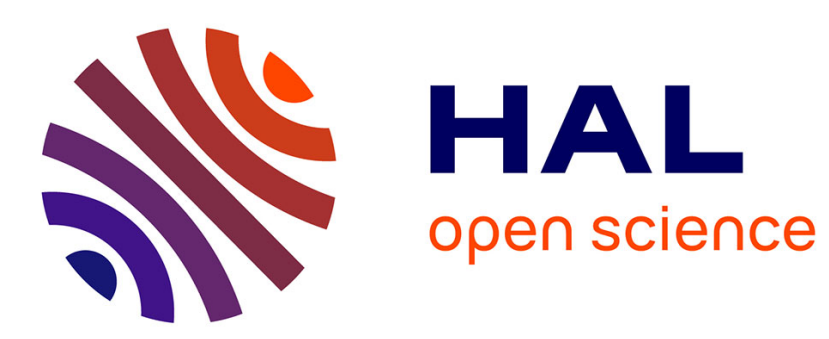

\title{
PULSED LASER ATOM PROBE CHARACTERIZATION OF SILICON CARBIDE
}

\author{
M. Miller, P. Angelini, A. Cerezo, K. More
}

\section{To cite this version:}

M. Miller, P. Angelini, A. Cerezo, K. More. PUlSED LASER ATOM PROBE CHARACTERIZATION OF SILICON CARBIDE. Journal de Physique Colloques, 1989, 50 (C8), pp.C8-459-C8-464. 10.1051/jphyscol:1989878 . jpa-00229976

\section{HAL Id: jpa-00229976 https://hal.science/jpa-00229976}

Submitted on 1 Jan 1989

HAL is a multi-disciplinary open access archive for the deposit and dissemination of scientific research documents, whether they are published or not. The documents may come from teaching and research institutions in France or abroad, or from public or private research centers.
L'archive ouverte pluridisciplinaire HAL, est destinée au dépôt et à la diffusion de documents scientifiques de niveau recherche, publiés ou non, émanant des établissements d'enseignement et de recherche français ou étrangers, des laboratoires publics ou privés. 
PULSED LASER ATOM PROBE CHARACTERIZATION OF SILICON CARBIDE

\author{
M.K. MILLER, P. ANGELINI, A. CEREZO* and K.L. MORE \\ Metals and Ceramics Division, Oak Ridge National Laboratory, Oak Ridge, \\ TN 37831, U.S.A. \\ * Department of Metallurgy and science of Materials, University of \\ oxford, GB-Oxford $O X 13 P H$, Great-Britain
}

\begin{abstract}
Field-ion microscopy and field evaporation of $\alpha$-SiC and $\beta$-SiC materials have been successfully demonstrated. Since field-ion micrographs could be taken immediately after pulsed field evaporation, the effects of preferential field evaporation of silicon that occurred under ramped field evaporation were eliminated. However, due to the high electrical resistivity of silicon carbide, conventional voltage pulsed field evaporation was not practical and pulsed laser field evaporation was required. No significant variations in performance were found as a function of laser wavelength but the full-width-at-half maximum mass resolution of $0.4 \mathrm{amu}$ was inferior to voltage pulsed field evaporation of metals. In addition, the background noise level was considerably higher. Within the statistical accuracy of the analyses, the compositions were found to be slightly deficient in silicon. These experiments also revealed that the laser power required to field evaporate $\mathrm{SiC}$ was greater than for other semiconducting materials.
\end{abstract}

\title{
INTRODUCTION
}

Silicon carbide is best known as a structural ceramic and is a material that has high temperature and high strength applications. Sintered or hot pressed silicon carbide ceramics are generally polycrystalline forms of $\alpha-\mathrm{SiC}$ which contain relatively small amounts of aluminum ${ }^{[1]}$ or boron ${ }^{[2]}$ intentionally added as densification aids. Silicon carbide, grown in whisker form, is also used as a high strength reinforcement in composites. ${ }^{[3]}$ The silicon carbide whiskers are cubic $\beta$-SiC and are usually grown by vapor-liquid-solid (VLS) or "rice-hull" processes. ${ }^{[+-6]}$ In addition, $\beta$-SiC has applications for use in semiconductor device applications because of its unique combination of physical and electronic properties. Single crystal thin films of $\beta-\mathrm{SiC}$ are currently grown by chemical vapor deposition onto (100) silicon substrates. ${ }^{[7]}$

Several previous attempts have been made to fabricate, image and analyze field-ion specimens of SiC with the atom probe field-ion microscope. As early as 1968, Nishida fabricated a blunt field emission specimen by electrolytic etching in a $\mathrm{NaOH}$ solution. ${ }^{[8]}$ Field-ion specimens of $5 \mu$ m diameter $\beta$-SiC whiskers were prepared by heating in an oxypropane flame for a few seconds. ${ }^{[9]}$ The silica bead that formed was then dissolved in hydrofluoric acid. Kudo et al. prepared field-ion specimens by electrolytically etching $\beta$-SiC whiskers in a solution of $45 \% \mathrm{HF}-22 \% \mathrm{H}_{2} \mathrm{SO}_{4}-22 \% \mathrm{H}_{3} \mathrm{PO}_{4}-11 \% \mathrm{CH}_{3} \mathrm{COOH}^{[10]}$ The same specimen preparation procedure was used by Nakamura and Kuroda in an atom probe investigation of [111] and [111]oriented whiskers. ${ }^{[1]}$ Nakamura et al. also prepared specimens by chemically etching whiskers in molten $\mathrm{KOH}^{\left[{ }^{[12]}\right.}$ Inoue and Nakada produced $\mathrm{SiC}$ needles with a end radius of $30 \mathrm{~nm}$ from whiskers by etching in a solution of $\mathrm{HF}$ and $\mathrm{HNO}_{3}{ }^{[13]}$ In the present atom probe field-ion microscopy investigation, several of these chemical methods were attempted on the various forms of $\mathrm{SiC}$ used in this study with little success. Therefore, a new approach to specimen preparation of these materials was taken that substituted ion milling for the conventional chemical or electrochemical procedures.

In a previous field-ion microscopy investigation of $\beta$-SiC, Smith found that the helium field-ion image was unstable and irregular although the ring structure of a low index pole was apparent when imaged in 
hydrogen..$^{[9]}$ Kudo et al. found that helium images of $\beta$-SiC were poor with no atomic order evident and hydrogen images were unstable and irregular..$^{[10]}$ A previous atom probe characterization of $\beta$-SiC whiskers was performed by Nakamura and Kuroda in a conventional voltage pulsed time-of-flight atom probe. ${ }^{[1]}$ However, only a very limited number of atoms were reported since the flight times were measured from an oscilloscope trace. The field evaporated species detected with a pulse fraction of $10 \%\left(\mathrm{~V}_{\mathrm{PULSE}} / \mathrm{V}_{\mathrm{DC}}\right)$ and a specimen temperature of $\sim 78 \mathrm{~K}$ in this instrument were $\mathrm{C}^{+}, \mathrm{Si}^{+}$, and $\mathrm{Si}^{2+}$ ions and $\mathrm{SiC}^{+}, \mathrm{SiC}^{2+}$ and $\mathrm{SiO}^{+}$ complex ions. The vacuum in this instrument was $\sim 10^{-6} \mathrm{~Pa}$. Carbon was found to evaporate in molecular form with silicon. However, a substantial proportion of ions shown in the mass spectra were unassigned. A voltage pulsed atom probe investigation of $\beta$-SiC at room temperature in the presence of approximately $10^{-5} \mathrm{~Pa}$ of hydrogen was performed by Nakamura et al. ${ }^{[12]}$ Under these conditions, the specimen field evaporated as $\mathrm{Si}^{2+}, \mathrm{C}^{+}, \mathrm{C}^{2+}$ and $\mathrm{H}^{+}$species. No complex species were observed; however, only a small number of ions were shown in the mass spectra.

\section{EXPERIMENTAL}

Field-ion specimens of polycrystalline $\alpha$-SiC, $\beta$-SiC thin films grown on (100) $\mathrm{Si}$, and $\beta$-SiC whiskers produced from the "rice-hull" and VLS processes were fabricated by ion milling. The bulk $\alpha$-SiC material was initially cut into square bars $(0.5 \mathrm{~mm} \times 0.5 \mathrm{~mm} \times 5 \mathrm{~mm})$ with a diamond cutoff wheel. The specimen blank was ion milled in a Gatan model 600 conventional ion mill in which the sample holder was adapted to accept the field-ion needles. The $\beta$-SiC/Si thin film specimens were prepared in a similar manner. This arrangement permitted the needle to be continuously rotated about its specimen axis during ion milling. A $6 \mathrm{kV}$ argon ion beam was used for ion milling. The whiskers were mounted onto blunt tungsten needles with conducting epoxy and were prepared in a Gatan model 645 precision ion milling system (PIMS) as described elsewhere. ${ }^{[4]}$

Field-ion microscopy was performed with specimen temperatures between 40 and $120 \mathrm{~K}$. Helium and neon image gases were used. However, because of the presence of a $\mathrm{C}^{3+}$ species at a mass-to-charge ratio of $4 \mathrm{amu}$ which would be masked by a $\mathrm{He}^{+}$species, helium was not used to image specimens that were intended for atom probe analysis.

Both the ORNL atom probe $e^{[15]}$ and Oxford University pulsed laser atom probe ${ }^{[16]}$ were used to examine the specimens. Chemical analyses were conducted primarily at Oxford University in the pulsed laser atom probe that is equipped with a JK Lasers System 2000 Neodymium-YAG laser. This laser features a $5 \mathrm{~ns}$ pulse width and has a power output of up to $120 \mathrm{~mJ}$ per pulse. Two wavelengths were used, 532 and $355 \mathrm{~nm}$. Chemical analyses were performed with the image gas removed from the system in a vacuum of better than $10^{-8} \mathrm{~Pa}$.

\section{RESULTS AND DISCUSSION}

\section{Ion Milling}

Most $\beta$-SiC field-ion specimens fabricated by ion milling were sharp, relatively uniform in cross-section, and had a small taper angle. The $\alpha$-SiC specimens were irregular in cross-section due to preferential ion milling along grain boundaries. A transmission electron microscope (TEM) image of a needle prepared from the $\beta$-SiC thin film is shown in Fig. 1. Ion milling consistently produced needles in which the end radius was less than $10 \mathrm{~nm}$.

\section{Field-Ion Microscopy}

A neon field-ion micrograph of an $\alpha$-SiC specimen taken after dc evaporation is shown in Fig. 2. The image was uniform over the specimen surface with little or no ring structure evident, in agreement with previous observations. No difference in behavior was observed between $\alpha$-SiC and $\beta$-SiC. Two field-ion micrographs taken immediately after pulsed laser field evaporation in vacuum are shown in Fig. 3 . The quality of these field-ion micrographs was slightly better and a few poles could be identified sufficiently to classify the major 111 pole from its 3-fold symmetry.

The calculated evaporation fields for $\mathrm{Si}^{+}, \mathrm{Si}^{2+}$, and $\mathrm{Si}^{3+}$ are 45,33 , and $60 \mathrm{Vnm}^{-1}$, respectively, and those of $\mathrm{C}^{+}, \mathrm{C}^{2+}$, and $\mathrm{C}^{3+}$ are 142,103 and $155 \mathrm{Vnm}^{-1}$, respectively. ${ }^{[17]}$ These values indicate that silicon is substantially easier to evaporate than carbon. It is likely that the silicon preferentially evaporates during 
dc evaporation leaving the surface of the specimen rich in carbon. The field-ion image of this surface is therefore not representative of silicon carbide but of carbon. Preferential field evaporation of one species is common in alloys that contain elements that differ significantly in their evaporation fields. ${ }^{[18]}$ After pulsed laser assisted field evaporation, the silicon was not preferentially evaporated from the surface of the specimen and a field-ion micrograph representative of $\mathrm{SiC}$ could be obtained.

\section{Atom Probe Analysis}

In these high resistivity materials, reliable voltage-pulsed field evaporation proved to be unattainable even with pulse fractions of over $100 \%$. Therefore, chemical analysis was performed in a pulsed laser atom probe. Specimens prepared from the $\beta$-SiC whiskers grown by the VLS process were used. The laser power required to field evaporate these specimens was greater than typical for other semiconducting materials. A series of atom probe experiments was performed to investigate whether the wavelength of the laser radiation or the specimen temperature significantly influenced the performance of the instrument or the accuracy of the composition determinations. Two mass spectra of a SiC whisker are shown in Fig. 4. The data in these mass spectra were collected with a specimen temperature of $70 \mathrm{~K}$ and a laser wavelength of (a) $355 \mathrm{~nm}$ and (b) $532 \mathrm{~nm}$. The charge state distributions for carbon and silicon ions are given in Table 1. Only minor differences in the charge state distributions were found between the experimental conditions. The silicon field evaporated almost exclusively as $\mathrm{Si}^{2+}$ with small amounts of $\mathrm{Si}^{+}$and $\mathrm{Si}^{3+}$. No molecular silicon species were observed. Approximately $80 \%$ of the carbon was found to field evaporate as $\mathrm{C}^{2+}$ and $\mathrm{C}^{+}$ions, although small amounts of $\mathrm{C}^{3+}$ and $\mathrm{C}_{2}$ and $\mathrm{C}_{3}$ molecular species were also observed. The quantity of ions in the molecular form was typical of that from a refractory carbide. The unusual presence of the triply-charged silicon and carbon ions is a consequence of the refractory nature of the carbide and the high field required to field evaporate the specimen at these temperatures.

Table 1. Distribution of ions between the charge states (in \%).

\begin{tabular}{|c|c|c|c|c|c|c|c|c|c|c|c|}
\hline Temperature & Wavelength & $\mathrm{Si}^{2+}$ & $\mathrm{Si}^{+}$ & $\mathrm{Si}^{3+}$ & $\mathrm{C}^{2+}$ & $\mathrm{C}^{+}$ & $\mathrm{C}^{3+}$ & $\mathrm{C}_{2}^{+}$ & $\mathrm{C}_{3}^{++}$ & $\mathrm{C}_{3}^{+}$ & $\mathrm{SiC}^{+}$ \\
\hline $95 \mathrm{I}$ & 53 & 98.1 & 1.4 & .5 & 56.5 & 24 & 2. & 4.0 & 13.0 & 0 & \\
\hline $70 \mathrm{~K}$ & 532 & 94.8 & 1.4 & 3.9 & 53.5 & 23.0 & 5.8 & 8.9 & 6.5 & 2.3 & 0.3 \\
\hline $40 \mathrm{~K}$ & 532 & 97.9 & 0.7 & 1.4 & 55.8 & 25.4 & 5.3 & 9.9 & 3.1 & 0.5 & 0.04 \\
\hline $70 \mathrm{~K}$ & 355 & 99.2 & 0.6 & 0.2 & 58.4 & 30.6 & 3.2 & 4.2 & 3.3 & 0.3 & 0.3 \\
\hline
\end{tabular}

A small number of ions were collected at a mass-to-charge ratio of $40 \mathrm{amu}$. This species could correspond to $\mathrm{SiC}^{+}$or $\mathrm{Ar}^{+}$ions. Since less than $0.3 \%$ of genuine ions were collected at this mass-to-charge ratio, its contribution may be either neglected or assigned to $\mathrm{SiC}$ without significantly altering the results. A few ions were also observed at mass-to charge ratios of 20,21 and 22 amu and were assigned to the image gas neon.

The composition determinations based on the assignments shown in Table 1 are summarized in Table 2 . The balance of these determinations was carbon. The error quoted is for one standard deviation. The peak at a mass-to-charge ratio of 12 amu was assigned exclusively to the $\mathrm{C}^{+}$ion and not the doubly charged $\mathrm{C}_{2}$ species. This assignment could result in a slight underestimate of the carbon level. The measured compositions under these conditions were consistent with each other within the statistical scatter. The average of the data sets indicated that there is a deficiency in silicon which possibly indicates a slight preferential evaporation of silicon, as would be anticipated from the difference in calculated evaporation fields. The whisker used in this experiment was grown by the VLS process and had a straight and uniform morphology. It has previously been observed that VLS whiskers of this type may possess excess carbon. ${ }^{\mid 6,19]}$ Therefore, the small deficiency in silicon measured by the atom probe may be real. Additional studies of a variety of $\mathrm{SiC}$ specimens of known chemistry are required.

The background noise in the mass spectra was higher than normal for metals in a voltage-pulsed energycompensated atom probe but similar to that obtained for semiconductors in a pulsed laser atom probe. The primary source of the background noise is residual image gas in the system. The mass resolution of $\Delta \mathrm{M} / \mathrm{M}$ of $\sim 1 / 35$ was also inferior to that observed with metal specimens $(\Delta M / M \simeq 1 / 600)$ and other semiconducting materials $(\Delta M / M \simeq 1 / 300)$. However, the severity of these degradations is not sufficient to limit atom probe analysis. 
Table 2. Pulsed Laser Atom Probe Composition Determinations in atomic percent. The balance of these analyses was carbon.

$\begin{array}{ccc}\begin{array}{l}\text { Specimen } \\ \text { Temperature }\end{array} & \begin{array}{c}\text { Wavelength } \\ \text { (nm) }\end{array} & \begin{array}{c}\text { Composition } \\ \text { (\% Si) }\end{array} \\ & & \\ 95 \mathrm{~K} & 532 & 49.1 \pm 2.1 \\ 70 \mathrm{~K} & 532 & 46.5 \pm 0.6 \\ 40 \mathrm{~K} & 532 & 47.8 \pm 0.8 \\ 70 \mathrm{~K} & 355 & 48.7 \pm 0.7\end{array}$

\section{SUMMARY AND CONCLUSIONS}

* Field-ion specimens of bulk, thin film and whisker $\mathrm{SiC}$ materials were successfully prepared by ion milling.

* De field evaporation results in a surface layer rich in carbon and anomalous field-ion micrographs.

* A pulsed laser atom probe is required for chemical analysis.

* The measured chemistry did not vary significantly with laser wavelength or specimen temperature.

* Silicon field evaporated as $\mathrm{Si}^{2+}$ with small amounts of $\mathrm{Si}^{+}$and $\mathrm{Si}^{3+}$.

* Carbon field evaporated predominantly as the $\mathrm{C}^{2+}$ and $\mathrm{C}^{+}$ions with small amounts of $\mathrm{C}^{3+}$ and molecular species.

\section{Acknowledgments}

The authors would like to thank Dr. G.D.W. Smith for use of the Pulsed Laser Atom Probe and K.F. Russell for her technical assistance. This research was sponsored by the Division of Materials Sciences, U.S. Department of Energy, under contract DE-AC05-84OR21400 with Martin Marietta Energy Systems, Inc.

\section{REFERENCES}

1. R. Hamminger, G. Grathwohl and F. Thummler, Sci. Ceram., $\underline{12}$ (1984) 425

2. K.L. More, C.H. Carter, J. Bentley, W.H. Wadlin, L. LaVanier and R.F. Davis, J. Amer. Ceram. Soc., $\underline{69}(1986) 695$.

3. G.C. Wei and P.F. Becher, Amer. Ceram. Soc. Bull., 64 (1985) 298.

4. J. Lee and I.B. Cutler, Amer. Ceram. Soc. Bull., 54 (1975) 195.

5. R.S. Wagner and W.C. Ellis, Appl. Phys. Lett., 4 (1964) 39.

6. J.V. Milewski, F.D. Gac, J.J. Petrovic and S.R. Skaggs, J. Mater. Sci., $\underline{20}$ (1985) 1160.

7. H.P. Liaw and R.F. Davis, J. Electrochem. Soc., 132 (1985) 642.

8. J. Nishida, J. Appl. Phys., $\underline{38}$ (1967) 5417.

9. D.A. Smith, J. Phys. E: Sci. Instrum., 2 (1969) 106.

10. J. Kudo, S. Nakamura and T. Kuroda, Jap. J. Appl. Phys., 14 (1975) 52.

11. S. Nakamura and T. Kuroda, Surf. Sci., 70 (1978) 452.

12. S. Nakamura, Y. Hasegawa, T. Hashizume and T. Sakurai, J. de Physique, 47-C7 (1986) 309.

13. T. Inoue and M. Nakada, J. de Physique, 48-C6 (1987) 595.

14. K.B. Alexander, P. Angelini and M.K. Miller, J. de Physique, this volume.

15. M.K. Miller, J. de Physique, 47-C2 (1986) 493.

16. A. Cerezo, G.D.W. Smith and A.R. Waugh, J. de Physique, 45-C9 (1984) 329.

17. T.T. Tsong, Surf. Sci., 70 (1978) 211.

18. M.K. Miller and G.D.W. Smith, "Atom Probe Microanalysis: Principles and Applications to Materials Problems," 1989, pub. Materials Research Society, Pittsburgh, Pa.

19. P.D. Shalek, D.S. Philips, D.E. Christiansen, J.D. Katz, W.J. Parkinson and J.J. Petrovic, in "Whisker and Fiber Toughened Ceramics," 1988, ed. R.A. Bradley, D.E. Clark, D.C. Larsen and J.O. Stiegler, pub. ASM International, Metals Park, OH, p. 53. 


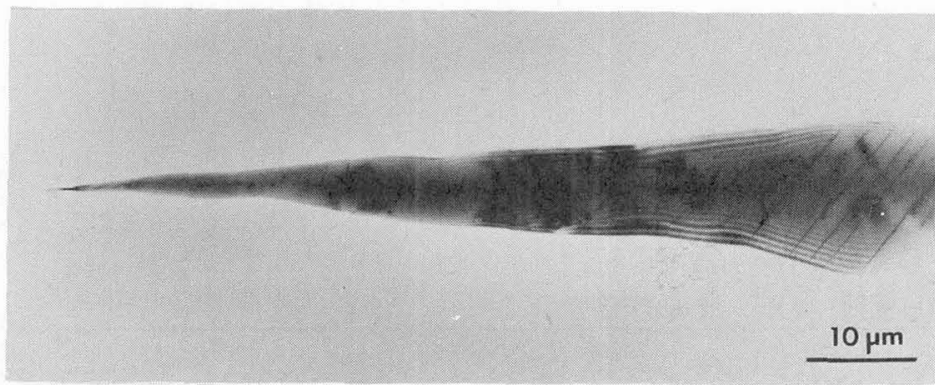

Fig. 1. Transmission electron micrograph of a needle prepared from a $\beta$-SiC thin film.
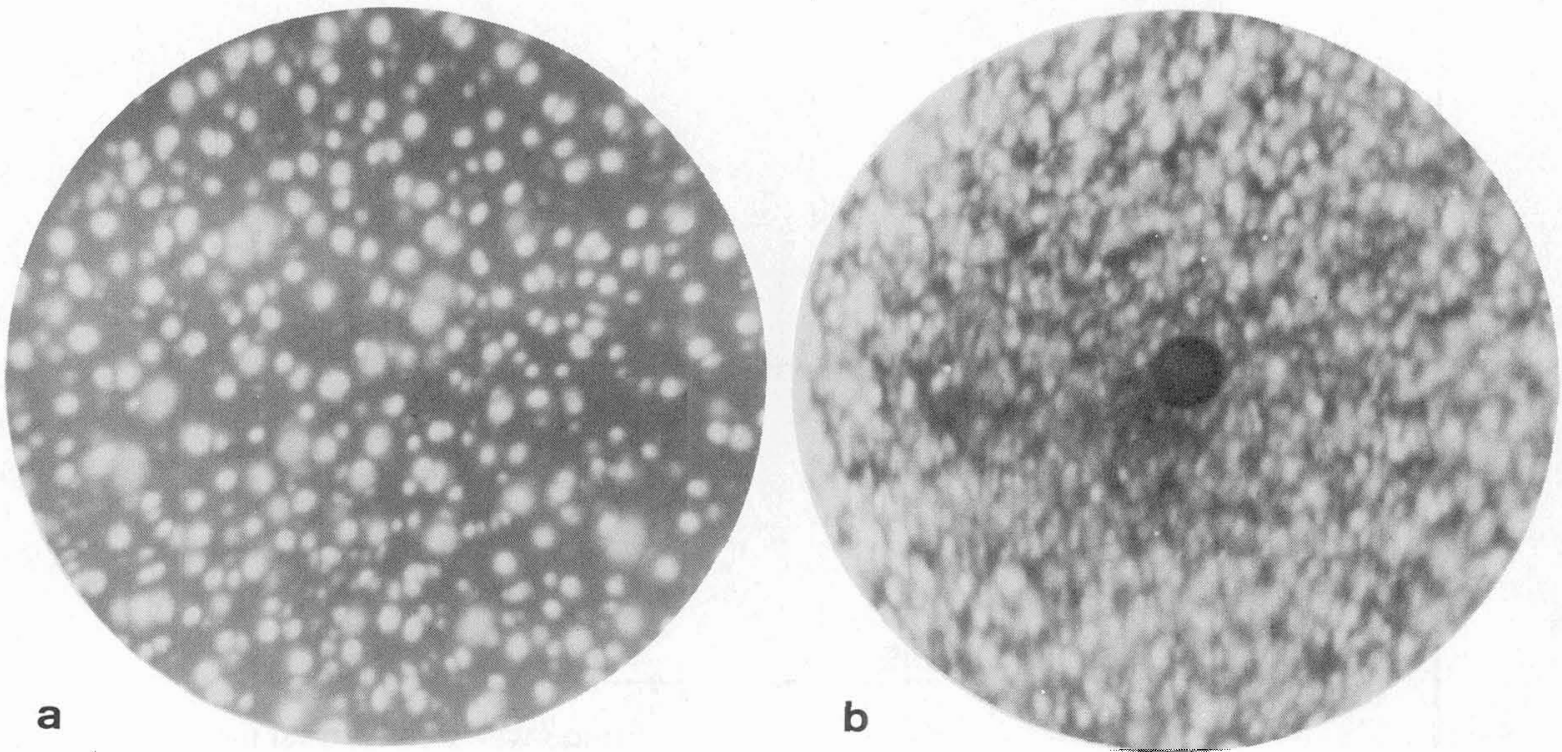

Fig. 2. Neon field-ion micrographs of a dc field evaporated $\alpha$-SiC specimen. (a) at best image voltage and (b) above best image voltage.
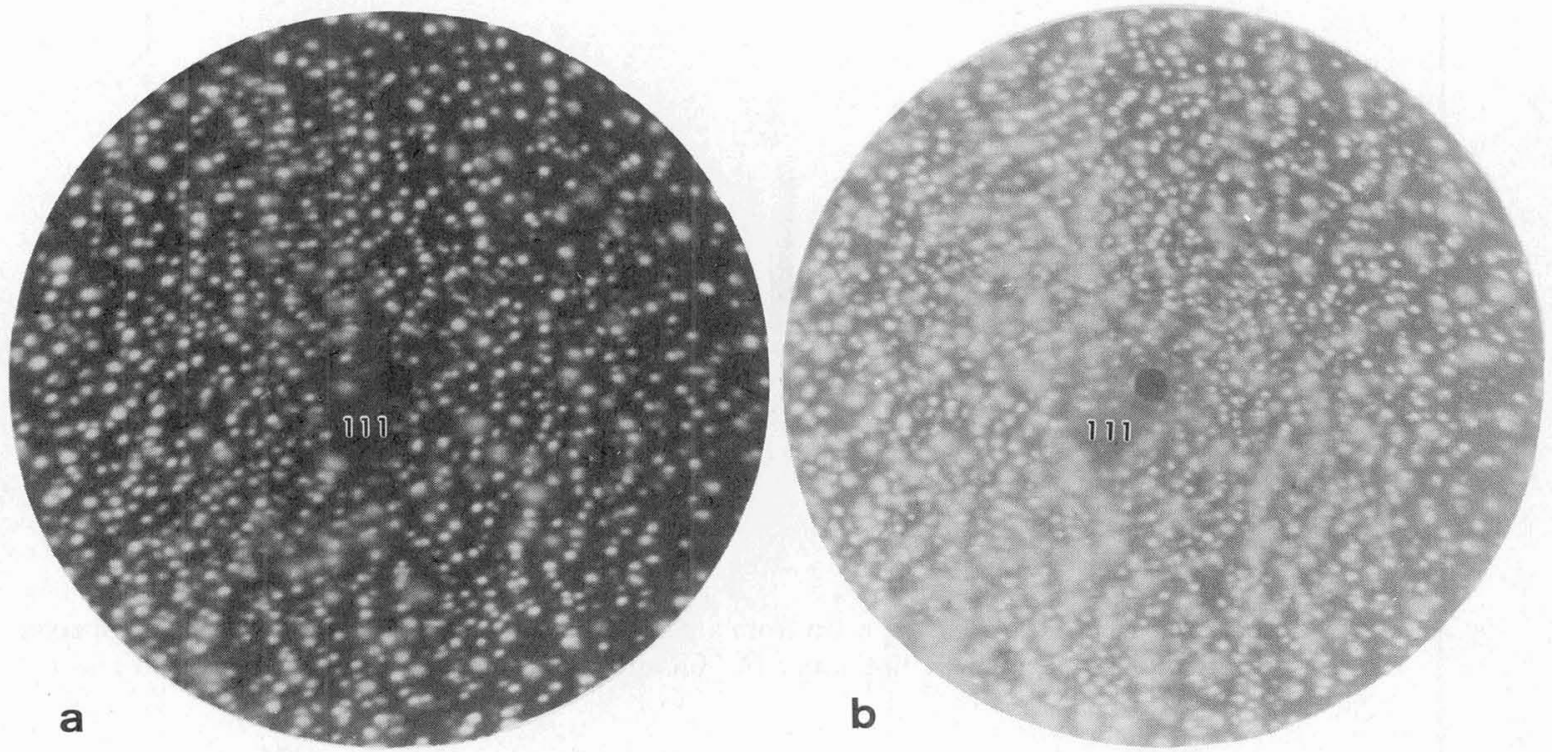

Fig. 3. Neon field ion micrographs of a $\beta$-SiC whisker after pulsed laser assisted field evaporation. (a) at best image voltage and (b) above best image voltage. 

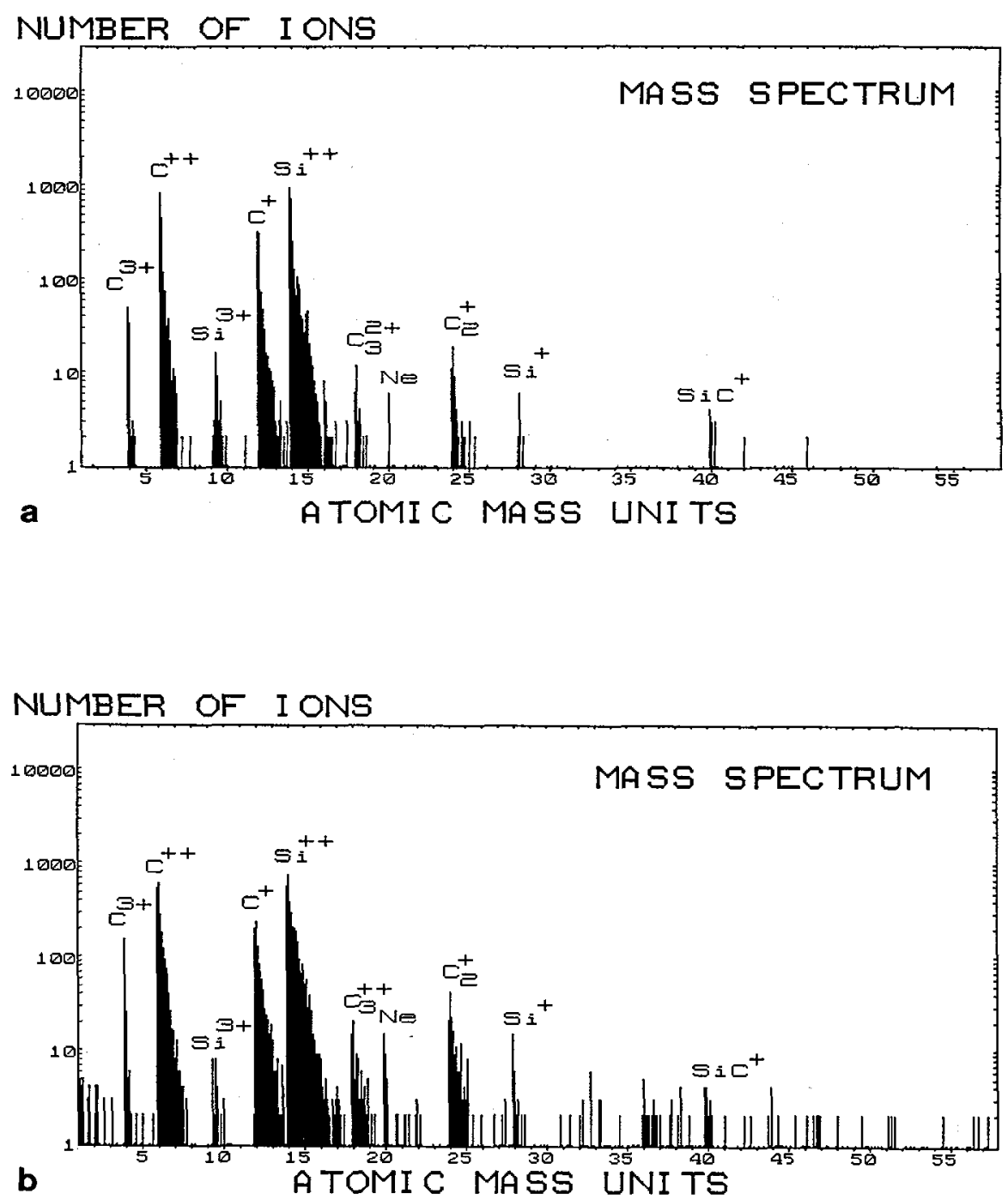

Fig. 4. Pulsed laser atom probe mass spectra from a $\beta$-SiC whisker grown by the VLS process. Spectra acquired with a specimen temperature of $70 \mathrm{~K}$ and laser wavelengths of (a) $355 \mathrm{~nm}$ and (b) $532 \mathrm{~nm}$. 